\title{
JOGO COMPUTACIONAL PARA APOIO A PESSOAS COM PARALISIA CEREBRAL
}

\author{
Jorlei Luis Baierle ${ }^{1}$ \\ Rejane Frozza ${ }^{2}$ \\ Beatriz Lux ${ }^{3}$
}

\begin{abstract}
RESUMO
Este artigo apresenta um jogo computacional educacional desenvolvido para atuar como uma nova tática de ensino em um ambiente virtual de aprendizagem com agentes pedagógicos emocionais, que executam diferentes funções. O jogo computacional tem como objetivo desenvolver o raciocínio lógico oferecendo desafios aos estudantes em um ambiente 3D, incluindo personagens tais como macacos, abelhas, jacaré, morcegos e gorila no trajeto de um trem que carrega mantimentos. O cenário do jogo possui elementos diversificados, tais como pontes, túnel, lago, floresta, montanhas e aldeia de índios. Este projeto visa contribuir no processo de ensino-aprendizagem, oferecendo um ambiente dinâmico e de interação com os estudantes, respeitando e adaptando-se às suas características de aprendizagem. Pretende-se adaptar o jogo desenvolvido para trabalhar com pessoas com deficiência física motora, mas com capacidade de aprendizagem, a fim de auxiliar com a sua inclusão em nossa sociedade.
\end{abstract}

Palavras-Chave: Jogo computacional. Ambiente educacional virtual. Inclusão. Paralisia cerebral.

\section{ABSTRACT}

This paper presents an educational computer game, developed to act as a new teaching tatic in a virtual environment with emotional pedagogical agents that perform different functions. The educational game aims to develop logical reasoning offering challenges to students, in a 3D environment, including characters such as monkeys, bees, alligator, bats and gorilla in the path of a train carrying provisions. The scenario of the game has several elements, such as bridges, tunnel, lake, forest, mountains and Indian village. This project contributes in teaching-learning process, which offers a dynamic environment of interaction with the students, respecting and adapting to their learning characteristics. It is intended to adapt the game developed to work with people with motor disabilities, but capable of learning, in order to assist their inclusion in our society.

Keywords: Computer game. Virtual educational environment. Inclusion. cerebral paralysis.

Aluno do Curso de Ciência da Computação - Bolsista (PIBITI/CNPq) - UNISC. E-mail: jorleib@mx2.unisc.br

2 Doutora em Ciência da Computação, professora do Departamento de Informática e do Programa de PósGraduação em Sistemas e Processos Industriais - UNISC

3 Mestre em Desenvolvimento Regional, professora do Departamento de Informática - UNISC. E-mail: lux@unisc.br 


\section{INTRODUÇÃO}

De acordo com (AZEVEDO; TAVARES, 2001), a aprendizagem é uma das atividades mais ricas desenvolvida pelo homem, devido à assimilação de novos conhecimentos. Geralmente, o local onde este aprendizado ocorre é na sala de aula, verificando, assim, a importância do papel do professor. Na visão de Silva e Heck (2008) experiências agradáveis, em relação à utilização de recursos tecnológicos nas atividades de ensino, têm sido relatadas por estudantes e professores.

As pessoas com deficiências físicas motoras são aquelas que apresentam limitações de mobilidade, quando comparadas ao indivíduo que possui todas as habilidades físicas mentais e neurológicas. Pessoas com desabilidades possuem os mesmos direitos das demais, e é neste ponto que surge o conceito de inclusão social, que é a adaptação da sociedade para que os indivíduos com deficiências sejam incluídos em todas as esferas da sociedade.

A acessibilidade em jogos de computador pode ser conceituada como a capacidade de participar plenamente do jogo apesar das limitações que apresentam os indivíduos com algum tipo de incapacidade. Deve-se levar em conta que jogos computacionais normalmente possuem interfaces complexas, que em geral são projetadas considerando pessoas com plenas habilidades, da mesma forma que os dispositivos desenvolvidos para a interação com estes jogos. Existem iniciativas que buscam conscientizar os desenvolvedores de jogos a levarem em conta alguns princípios de acessibilidade para tornar o acesso aos jogos mais universal. Tais iniciativas são, em sua maioria, não comerciais e têm divulgado trabalhos que propõem diferentes formas de interação entre pessoas com limitações de mobilidade e jogos eletrônicos, incluindo dispositivos especiais e ferramentas de software ou combinações de ambos, para proporcionar melhor acesso a estes indivíduos.

O desenvolvimento de jogos computacionais educacionais pode proporcionar uma melhoria dos processos de ensino-aprendizagem, já que motiva o interesse de interação dos usuários com o sistema computacional. Neste sentido, um dos objetivos do projeto versa sobre a modelagem e o desenvolvimento de um jogo computacional educacional, que atenda às necessidades especiais do estudante em relação à paralisia cerebral, sem perda das suas capacidades cognitivas, a ser utilizado como estilo cognitivo no ambiente virtual de aprendizagem desenvolvido nesta pesquisa.

$\mathrm{O}$ jogo computacional desenvolvido é em 3D e refere-se às habilidades de raciocínio lógico, apresentando conceitos básicos, desafios a serem cumpridos e problemas a resolver, durante a interação dos estudantes com o sistema.

O artigo está organizado nas seguintes seções: os temas relativos à inclusão e deficiência; as características gerais do ambiente educacional virtual desenvolvido; os jogos computacionais na educação; as características do jogo educacional proposto e desenvolvido; e as conclusões.

\section{A RELAÇÃO INCLUSÃO E DEFICIÊNCIA}

O artigo 10 da declaração universal dos direitos humanos diz "Todos os seres humanos nascem livres e iguais em dignidade e em direitos. Dotados de razão e de consciência, devem agir uns para com os outros em espírito de fraternidade." (ONU, 2008). Este princípio deveria bastar para que todos os indivíduos fossem tratados de forma igualitária e para que a todos fossem dadas as mesmas condições de vida. 
No entanto, a maior parte do que é construído pela sociedade, é produzido a partir dos referenciais do chamado "homem-padrão", que segundo (VITAL; QUEIROZ, 2008) é "possuidor de todas as habilidades físicas, mentais e neurológicas.". Conforme o texto faz-se necessária uma visão que considera o acesso universal. Ainda que o autor estivesse se referindo ao espaço físico, este conceito pode ser extrapolado a todo o tipo de projeto, seja ele de um prédio, de uma máquina ou mesmo de um sistema de informação.

Para se ter ideia das dificuldades que se deve ter em mente ao se projetar um ambiente acessível, a Convenção sobre os Direitos das Pessoas com Deficiências define no Artigo 1ㅇ que:

\begin{abstract}
Pessoas com deficiência são aquelas que têm impedimentos de longo prazo de natureza física (motora), mental, intelectual ou sensorial, os quais, em interação com diversas barreiras, podem obstruir sua participação plena e efetiva na sociedade em igualdades de condições com as demais pessoas. (ONU, 2008).
\end{abstract}

De acordo com IGDA (acrônimo de International Game Developers Association, 2011), as principais categorias de incapacidades encontradas na prática de jogos eletrônicos são limitações na visão, audição, mobilidade, ou problemas cognitivos. Considerando o fato de que este trabalho será focado em indivíduos com deficiências físicas motoras que mantêm suas capacidades cognitivas, esta categoria de incapacidades será tratada em maior detalhe.

Conforme Diehl (2006), "pessoas com deficiências físicas (motoras) podem ser classificadas, de forma aproximada, como aquelas que possuem algum tipo de comprometimento para a realização dos padrões motores esperados". As origens da deficiência física podem ser de ordem cerebral, medular, muscular, e ósseo-articular e os efeitos no indivíduo incluem as deficiências físicas como lentidão gestual e movimentos involuntários, paralisia parcial ou total, malformações e amputações.

Segundo Sassaki (2005), a inclusão social é "o processo pelo qual a sociedade se adapta para poder incluir, em seus sistemas sociais gerais, pessoas com necessidades especiais e, simultaneamente, estas se preparam para assumir seus papéis na sociedade".

Em sua visão, Kiehl (2010) afirma que "nos dias atuais, o paradigma da inclusão deve levar o indivíduo a ser caracterizado pelo respeito às diferenças, isto é, respeito às pessoas que apresentam deficiência, dando-lhes o direito de ser parte da sociedade".

Segundo Vital e Queiroz (2008), a Convenção Sobre os Direitos das Pessoas com Deficiência se "refere à acessibilidade como ferramenta para que as pessoas com deficiência atinjam sua autonomia em todos os aspectos da vida". Dessa forma, pode-se considerar a acessibilidade como uma ferramenta para a inclusão social.

Na visão de IGDA (2011),

a acessibilidade em jogos pode ser definida como a habilidade de jogar um jogo
mesmo quando operando sob condições limitantes. Condições limitantes podem
ser limitações funcionais, ou desabilidades - tais como cegueira, surdez, ou
limitações de mobilidade.

Devido ao fato dos resultados do Censo 2010 terem sua divulgação prevista para o primeiro trimestre de 2012 (IBGE, 2010), os números disponíveis são do Censo Demográfico 2000 realizado pelo IBGE. Conforme estes números, o Brasil possui 24.600 .256 pessoas portadoras de deficiências. Este número representa aproximadamente $14,5 \%$ do total da 
população registrada na época. Deste total de pessoas com incapacidades, 1.416 .060 possuem algum tipo de deficiência física. Sendo assim, mesmo levando-se em conta estes números desatualizados, pode-se ter uma ideia da demanda existente para jogos computacionais acessíveis aos incapacitados, tanto para serem utilizados como entretenimento quanto para uso educacional ou em tratamentos de reabilitação.

As primeiras iniciativas relacionadas à acessibilidade são tão antigas quanto os próprios jogos eletrônicos. No entanto, são trabalhos isolados, de pessoas envolvidas com portadores de deficiências que improvisavam dispositivos para proporcionar algum nível de usabilidade a estes indivíduos.

Conforme IGDA (2011), as principais maneiras de melhorar a acessibilidade de um jogo, focando em dificuldades motoras são: permitir que todos os controles sejam remapeados, possibilitando que o jogador jogue da forma mais confortável possível; prover documentação em formato acessível, como html ou texto puro, por exemplo; e disponibilizar modos auxiliares, como mira automática e opções de treinamento, entre outros; disponibilizar uma ampla gama de níveis de dificuldade, para evitar que o jogador se frustre por não conseguir avançar no jogo; permitir o ajuste da velocidade do jogo conforme o tempo de reação do jogador, também para evitar sua insatisfação.

Desta forma, tornar um jogo universalmente acessível é uma tarefa difícil, pois se deve lidar com uma grande variedade de dificuldades. Mesmo assim, um jogo computacional pode ser desenvolvido com estas habilidades, atendendo e contribuindo de forma lúdica aos indivíduos com incapacidades motoras.

\section{AMBIENTE VIRTUAL EDUCACIONAL E AS TÁTICAS DE ENSINO}

O ambiente educacional virtual desenvolvido pelo grupo de pesquisa do projeto tem a atuação dos agentes pedagógicos emocionais Dóris (agente tutor) e Dimi (agente companheiro), baseado em estilos cognitivos para adaptação às características de aprendizagem dos usuários (estudantes e público em geral) (FROZZA et al, 2011). A Figura 1 apresenta uma das telas do ambiente, com o conteúdo instrucional do domínio da coleta seletiva e compostagem.

Figura 1 - Tela do ambiente educacional virtual com os agentes pedagógicos Dóris e Dimi.

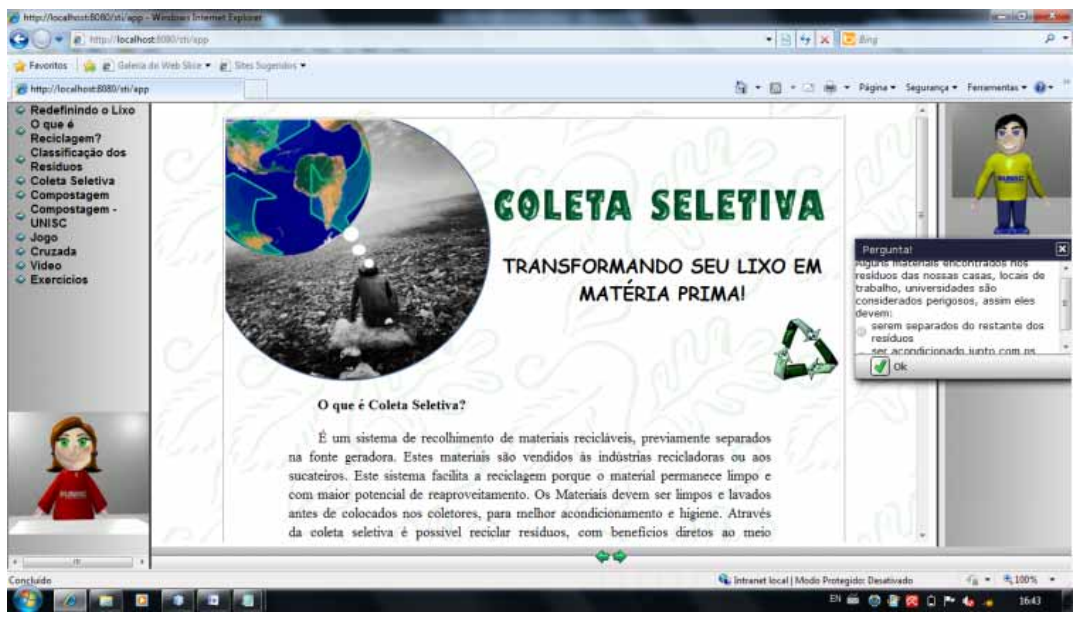


Neste ambiente, tem se o intuito de adicionar o jogo computacional desenvolvido. Os jogos computacionais podem também ser utilizados em ambientes educacionais virtuais como tática de ensino, contribuindo de forma eficiente para estimular as atividades dos usuários.

\section{JOGOS COMPUTACIONAIS NA EDUCAÇÃO}

Estudos direcionados à utilização de jogos computacionais no aprendizado vêm sendo feitos por vários pesquisadores, tanto a nível nacional, quanto internacional.

$O$ atrativo dos jogos, em uma primeira avaliação, pode ser interpretado pelas suas características mais conhecidas: ludicidade, apresentação de desafios, competitividade. A possibilidade, porém, de desenvolver ambientes virtuais integrando várias mídias (animação, vídeo, áudio, texto), segundo (BATTAIOLA; ELIAS; DOMINGUES, 2002), "origina as apresentações multimodais e o efeito da atenção dividida". Este efeito, segundo o autor, facilita o aprendizado porque a memória humana processa melhor as informações se forem apresentadas em dois modos diferentes, visual e auditivo. Outra característica importante é salientada por (GOSUEN, 2004) que analisa a importância do papel do inter-ator nos universos digitais interativos, dos quais depende a conclusão da narrativa. $O$ aluno, pode se perceber como parte do ambiente em um processo de imersão interno, onde atuará como personagem principal, realizando uma "simulação subjetiva", assim explicada pelo autor:

\footnotetext{
Esta simulação subjetiva poderia estar relacionada não apenas ao nosso desejo de explorar conteúdos possíveis em nosso mundo real, mas nas novas possibilidades até então impensadas e evidenciadas pelo prazer de nos preservarmos através da ideia de recursividade oferecida pelo meio digital, ou seja, a possibilidade de podermos recomeçar novamente uma situação experimentada independente do seu resultado. (GOSUEN, 2004).
}

A autora (ROLAND, 2004) salienta a importância dos jogos em nossa vida desde a infância e o fato de facilitarem o aprendizado por serem motivadores e divertidos. Segundo a autora:

\footnotetext{
Jogar é participar de um mundo de faz de conta, dispor-se às incertezas e enfrentar desafios em busca de entretenimento. Através do jogo se revelam a autonomia, criatividade, originalidade e a possibilidade de simular e experimentar situações perigosas e proibidas ao nosso cotidiano.
}

Também, o ensino utilizando meios lúdicos cria ambientes gratificantes e atraentes servindo como estímulo para o desenvolvimento integral. O autor coloca que um jogo educativo computadorizado é um ambiente de aprendizagem que une as características dos jogos com as de software, agregando memória (visual, auditiva, sinestésica); orientação temporal e espacial (em duas e três dimensões); coordenação motora viso manual (ampla e fina); percepção auditiva, percepção visual (tamanho, cor, detalhes, forma, posição, lateralidade, complementação), raciocínio lógico-matemático, expressão linguística (oral e escrita), planejamento e organização.

Porém, nem todos os jogos possuem as qualidades necessárias para serem considerados atraentes e prenderem a atenção dos usuários. Buscou-se definir quais seriam as características importantes para tornar um jogo uma atividade interessante e prazerosa. 
Segundo (HUIZINGA, 2004), são cinco as características, como descrito a seguir:

- Liberdade: O jogo não deve ser uma atividade obrigatória, joga-se pelo prazer de jogar.

- Absorção: O jogo conduz para uma esfera "faz de conta", absorvendo completamente o jogador.

- Isolamento: Possuir seus próprios limites de tempo e de espaço. Há, diretamente ligada à sua limitação no tempo, uma característica interessante no jogo, a de se fixar imediatamente como fenômeno cultural. Mesmo depois de o jogo ter chegado ao fim, ele permanece como uma criação nova do espírito, um tesouro a ser conservado pela memória.

- Ordem: Para o autor "o jogo cria ordem e é ordem", criando uma "perfeição temporária e limitada" na imperfeição do mundo real.

- Agrupamento: O jogo facilita a formação de comunidades de jogadores, que compartilham segredos e possuem "a sensação de estar separadamente juntos".

A definição do jogo poderia ser, resumindo estas características citadas, como uma atividade ou ocupação voluntária, exercida dentro de limites de tempo e de espaço, segundo regras livremente consentidas, mas absolutamente obrigatórias e dotadas de um fim em si mesmo, acompanhado de um sentimento de tensão e de alegria e de uma consciência de ser diferente da vida quotidiana (HUIZINGA, 2004).

\section{METOdOLOGIA}

A metodologia aplicada refere-se a uma pesquisa de natureza descritiva, já que descreve o ambiente educacional virtual que integrará o jogo computacional como tática de ensino. Também uma pesquisa de natureza exploratória, pois é baseada em estudos teóricos sobre inclusão e deficiência e como os jogos computacionais podem ser desenvolvidos para melhoria do processo de ensino-aprendizagem para pessoas deficientes.

Para o andamento da pesquisa, foram definidos objetivos para o desenvolvimento prático do jogo computacional, abordando a história do jogo, seus componentes, personagens e desafios. A fim de atingir os resultados esperados, foram realizados:

- Estudos abrangendo novos conhecimentos em relação à inclusão de pessoas com deficiências físicas.

- Estudos para a instalação de softwares necessários para o funcionamento do jogo computacional.

- Estudos para realização da modelagem e desenvolvimento do jogo proposto.

- Reuniões para avaliar o andamento da pesquisa e os resultados parciais. 


\section{O JOGO COMPUTACIONAL EDUCACIONAL DESENVOLVIDO}

Dentre as pesquisas na área de jogos computacionais realizadas pelo Departamento de Informática da Universidade de Santa Cruz do Sul, destaca-se o trabalho envolvendo o desenvolvimento de um jogo computacional para raciocínio lógico (LUX et al, 2008). Este projeto envolveu ampla pesquisa para desenvolvimento de um roteiro que atendesse aos requisitos básicos de um jogo computacional motivador, onde o aprendizado fosse subjacente ao prazer de jogar e que permitisse ao usuário enfrentar desafios motivadores que implicassem no aperfeiçoamento do raciocínio lógico.

O roteiro do jogo foi desenvolvido buscando apresentar desafios que possibilitem o desenvolvimento do raciocínio lógico, combinado com cálculos matemáticos, envolvendo as operações básicas. Desta forma, para atingir o desafio de entregar mantimentos em uma aldeia indígena distante e isolada pelas intempéries, o jogador necessita escolher o trajeto a ser seguido e as armas que poderão auxiliá-lo a atingir seu objetivo.

Os desafios estão relacionados a animais presentes no trajeto, que roubam carga ou impedem a passagem do trem e também a condições climáticas adversas.

O primeiro desafio se dá logo no início do percurso, quando a locomotiva encontra um trecho de trilhos que está danificado (a chuva fez rolar pela encosta). Na interface haverá como opção comunicar-se textualmente, solicitando o material necessário para o conserto. Após chegarem os vagões com o material, o usuário realizará o conserto descrevendo textualmente a sequência de operações necessárias para efetuá-lo.

A seguir, a locomotiva chega a um depósito onde pode carregar vagões com mantimentos e carvão. Cada vagão terá um peso relativo à sua carga, que é visualmente mostrado, não podendo o total de carga superar determinado valor. O jogador deverá optar pela proporção de peso entre mantimentos e carvão.

Na sequência, acontecem as situações envolvendo obstáculos, escolhas e raciocínio, onde o jogador precisará preocupar-se em ter carvão suficiente para chegar ao destino (o que representa a sua vida) e entregar um bom peso de mantimentos para atingir uma pontuação alta.

O objetivo do jogo é auxiliar na abstração de conceitos relacionados ao raciocínio lógico, matemático e computacional, como variáveis e funções lógicas, comandos de seleção e de repetição. $O$ jogo é em 3D e envolve um jogador. O seu gênero é educacional e estratégico.

Os personagens do jogo são o protagonista, que é maquinista de uma locomotiva a vapor, e os antagonistas, que se referem ao ataque de animais e dificuldades advindas de condições climáticas. $O$ objetivo é entregar a maior carga possível de mantimentos na aldeia dos índios e quanto maior for esta carga, maior será a pontuação final.

O jogo apresenta ao usuário a missão de entregar mantimentos em uma aldeia indígena distante, isolada pelas consequências de um inverno rigoroso. A ideia do roteiro baseia-se em buscar uma analogia entre vagões do trem com espaço em memória para armazenagem de dados (variáveis); e o percurso do trem como o fluxo de execução em um algoritmo (conjunto de passos para resolução de problemas, envolvendo raciocínio lógico). 
Algumas regras foram definidas para o jogo: a locomotiva somente poderá andar nos trilhos; os deslocamentos permitidos são para frente, esquerda e direita (nos entroncamentos).

As ações de defesa sempre envolverão um decréscimo de carga (mantimentos ou carvão). O jogador poderá visualizar a qualquer momento o total disponível de carga e mantimentos.

Em relação ao ambiente, o jogo é em visualização em 3D, ambiente externo, representando planícies, montanhas, florestas; a atuação do usuário em primeira pessoa (ou avatar); a locomotiva é no estilo antigo, a vapor, puxando vagões de carga abertos.

Além da visualização do cenário e atores em 3D, é disponibilizada uma representação em 2D, no painel de comandos onde o maquinista encontrará as opções para sua atuação no jogo. São elas: Teletipo - para solicitar recursos e escrever a sequência de passos para resolução de uma tarefa; Carregar - para colocar mantimentos e/ ou carvão nos vagões; Descarregar - para retirar mantimentos e/ ou carvão nos vagões; Lançar fumaça - defesa contra animais; Lançar vapor - defesa e derreter neve; Ligar o refletor de luz da locomotiva; Carga - informa total de mantimentos e combustível nos vagões.

A Figura 2 apresenta quatro imagens do cenário do jogo, com uma visão geral, os trilhos, o trem e a aldeia dos índios.

Figura 2 - Cenários do jogo computacional.

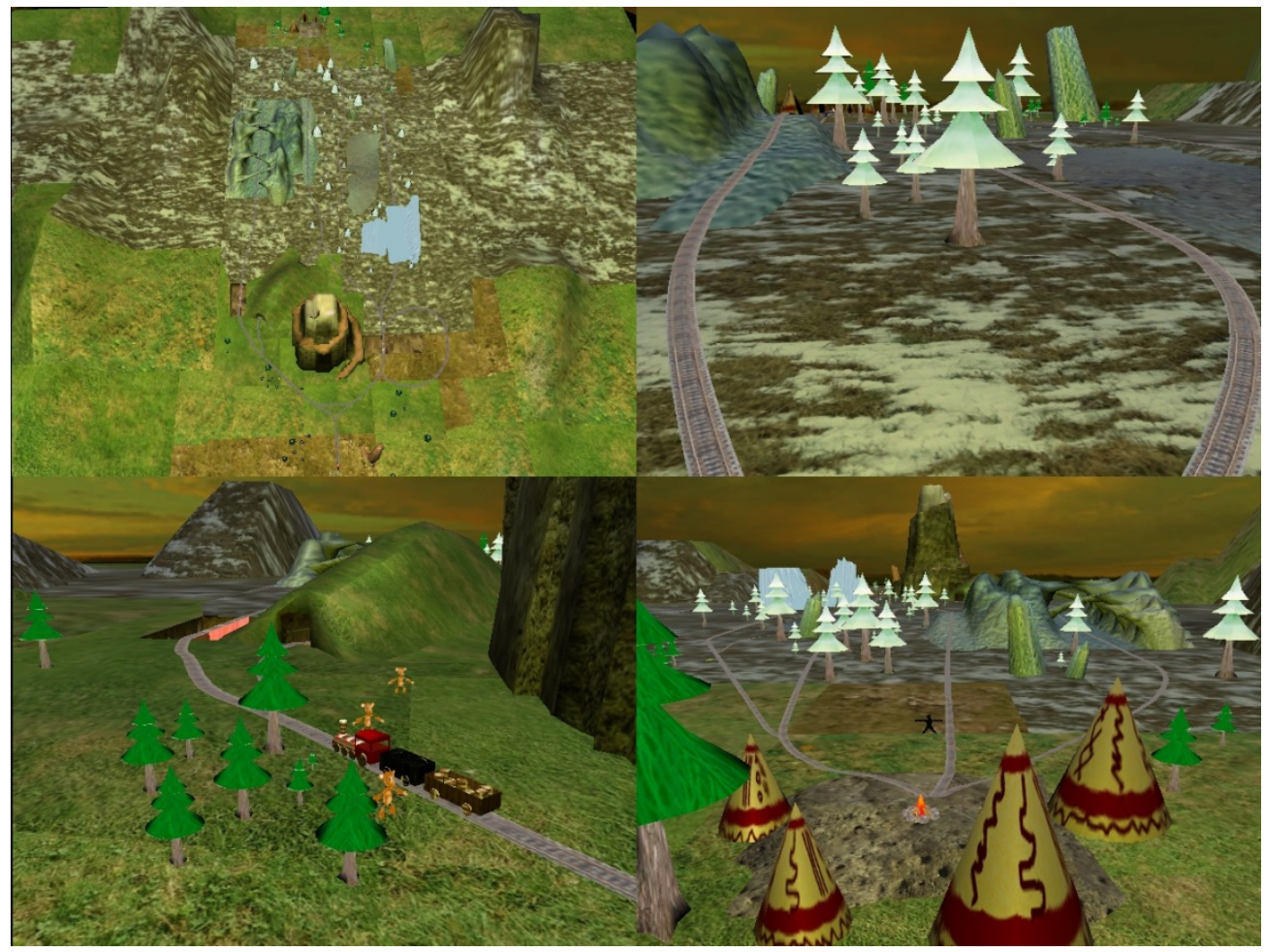


O jogo teve completo desenvolvimento quanto à modelagem dos diversos elementos gráficos (cenário, vegetação, locomotiva, animais) e foi implementado utilizando a ferramenta Blender (http://www.blender.org).

Com o mesmo método utilizado para identificar a malha dos trilhos e possibilitar o percurso do trem, foram desenvolvidas funções capazes de manter uma câmera acompanhando constantemente o trem.

A Figura 3 apresenta quatro imagens da câmera posicionada junto ao trem, permitindo a visualização de alguns animais (abelhas e macacos).

Figura 3 - Diferentes visões do trem.

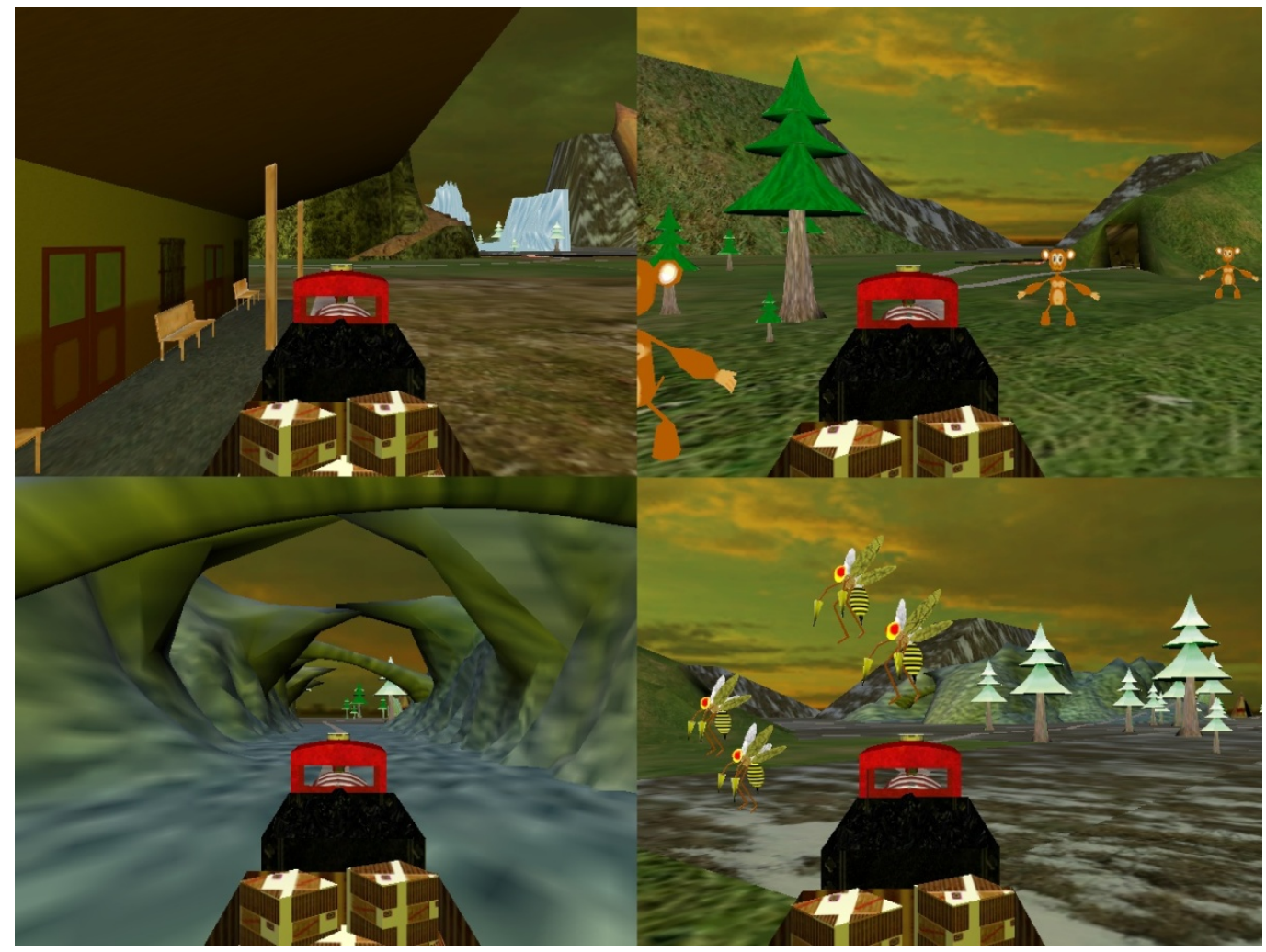

\section{CONCLUSÕES}

A utilização de ambientes educacionais como prática pedagógica para o desenvolvimento cognitivo vem proporcionando atividades desafiadoras que oferecem maior motivação e entusiasmo nos processos de ensino-aprendizagem. Esta pesquisa contribui no processo de ensino-aprendizagem, oferecendo um ambiente dinâmico de interação com os estudantes e motivando-os na realização de atividades propostas com o uso de agentes pedagógicos emocionais.

Apesar dos esforços de alguns pesquisadores e de entidades voltadas ao apoio da inclusão de tecnologias apropriadas e facilitadoras ao ensino de pessoas com incapacidades físicas advindas de paralisia cerebral, ainda é pequeno o número de instituições de ensino que possuem hardware e software apropriado. 
Neste sentido, a presente pesquisa está em constante desenvolvimento da adaptação de um jogo educacional que, juntamente com as características intrínsecas de ludicidade que os jogos devem proporcionar, também permite um acréscimo no desenvolvimento de habilidades motoras adaptadas e cognitivas.

O uso do jogo pedagógico computacional baseado em raciocínio, a ser utilizado como estilo cognitivo no ambiente virtual de aprendizagem, auxiliará os estudantes a compreender melhor o ensino com esta metodologia e auxiliará no tratamento de pessoas com paralisia cerebral. Como o jogo não está totalmente concluído, ainda não foi realizada uma validação. Como atividades futuras, serão realizadas: validação do ambiente com o jogo computacional desenvolvido com, pelo menos, uma pessoa com paralisia cerebral sem comprometimento mental; realização de ajustes e testes no ambiente; e escrita de outros artigos relacionados ao projeto.

Ter participado desta pesquisa e ser agraciado com o prêmio Honra ao Mérito da Iniciação Científica da UNISC, além de aprofundar os conhecimentos no mundo dos jogos no âmbito acadêmico, fez-nos refletir sobre o contato das pessoas deficientes com esta vasta gama de jogos, inicialmente disponibilizados às pessoas ditas normais, e a possibilidade de oferecer alternativas de utilização de jogos computacionais às pessoas com incapacidades.

Conforme Maiara Halmenschlager, aluna do curso de Jornalismo da Universidade de Santa Cruz do Sul, em entrevista com os integrantes desta pesquisa, após a apresentação no XVII Seminário de Iniciação Científica da UNISC em 2011, "Se você que está lendo este texto com facilidade, entendendo palavra por palavra do que está escrito, provavelmente também conseguiria acessar um jogo computacional na internet, fazer uso das ferramentas que ele oferece e atingir os objetivos propostos pela brincadeira, porém, nem sempre é assim. Para muitas pessoas que possuem alguma incapacidade, ler um texto ou manusear um mouse e as teclas de um teclado - para se divertir e aprender por meio de um jogo - é uma tarefa que muitas vezes exige esforço, tornando-se um desafio". Após sua conclusão, o jogo computacional beneficiará pessoas com paralisia cerebral através da motivação, fazendo com que estas pessoas se sintam capazes de realizar atividades, mesmo sem algum tipo de movimento, já que possuem capacidade de raciocínio, ficando motivadas, além de exercer o raciocínio e estar aprendendo.

\section{REFERÊNCIAS}

AZEVEDO, B. F. T.; TAVARES, O. de L. Um Ambiente Inteligente para Aprendizagem Colaborativa. 2001. Workshop em Informática na Educação (SBIE) 2001331 XII Simpósio Brasileiro de Informática na Educação - SBIE - UFES, 2001. p. 331-339.

BATTAIOLA, A. L., ELIAS, N. C., Domingues, R. de G.. Um Software Para Ensino de Conceitos de Computação Gráfica. Revista Brasileira de Aprendizagem Aberta e a Distância, São Paulo, Agosto de 2002. p. 1-10. Disponível em <http://www.abed.org.br/revistacientifica/ Revista_PDF_Doc/2002_Software_Ensino_Andre_Battaiola_Chamel_Elias_Rodrigo_Domingu es.pdf>. Acesso em: 14 mai. 2010.

BLENDER: ferramenta open source para desenvolvimento de aplicações gráficas. Disponível em <http://www.blender.org $>$. 
DIEHL, Rosilene Moraes. Jogando com as diferenças: jogos para crianças e jovens com deficiência : em situação de inclusão e em grupos específicos. 6. ed. São Paulo: Phorte, 2006.

FROZZA, R. et al. Agentes Pedagógicos Emocionais atuando em um Ambiente Virtual de Aprendizagem. RENOTE - Revista Novas Tecnologias na Educação , v.9, p.1 - 10, 2011.

GOSUEN, Luciano. Artigo: Estado da Arte - Narrativas Interativas. Programa Conexões Científicas, LIDEC, USP, 2004. Disponível em <http://www.lidec.futuro.usp.br/conexoes.php>.

HUIZINGA, Johan. Homo ludens: o jogo como elemento da cultura. 5. ed. São Paulo: Perspectiva, 2004.

IBGE. Censo Demográfico 2010 - Primeiros Resultados - População e Domicílios Recenceados. 2010. Disponível em: <http://www.ibge.gov.br/home/presidencia/noticias /imprensa/ppts/0000000237.pdf>. Acesso em: 26 março 2011.

IGDA. Accessibility in Games: Motivations and Approaches. 2004. Disponível em: <http://archives.igda.org/accessibility/IGDA_Accessibility_WhitePaper.pdf>. Acesso em: 19 março 2011.

KIEHL, Maria Eugênia Malheiros. Análise da acessibilidade em instituição de ensino superior à pessoa cega. 2010. 132 f. Dissertação (Programa de Pós-Graduação em Reabilitação e Inclusão Mestrado Profissional em Reabilitação e Inclusão) - Centro Universitário Metodista, Porto Alegre, 2010.

LUX, B. et al. O desafio de desenvolver um roteiro para jogo computacional 3D voltado ao aprendizado de algoritmos. In: SBIE, 2008, Fortaleza. II Workshop de Ambientes de apoio à Aprendizagem de Algoritmos e Programação. Fortaleza, 2008.

ONU. Declaração Universal dos Direitos Humanos. Assembléia das Nações Unidas. 1948. In: RESENDE, A. P. C. de; VITAL, F. M. de P. (Org.). A convenção sobre os Direitos das Pessoas com Deficiência Comentada. Brasília: CORDE, 2008. p. 121-127.

SASSAKI, Romeu Kazumi. Inclusão: construindo uma sociedade para todos. 6. ed. Rio de Janeiro: WVA, 2005.

SILVA, J. M. C. da; HECK G. Utilizando o questionário MSLQ para identificação de estados afetivos em um ambiente virtual de aprendizagem. In: I Seminário de Tecnologia da Informação Aplicada, 2008, Chapecó. I Seminário de Tecnologia da Informação Aplicada, 2008.

ROLAND, L.C. et al. Jogos Educacionais. Revista Novas Tecnologias na Educação. v. 2, n.1, mar. 2004.

VITAL, F. M. de P.; QUEIROZ, M. A. de. Artigo 9 - Acessibilidade. In: RESENDE, A. P. C. de; VITAL, F. M. de P. (Org.). A convenção sobre os Direitos das Pessoas com Deficiência Comentada. Brasília: CORDE, 2008. p. 44-47. 


\section{Agradecimentos}

Os autores expressam o seu reconhecimento ao CNPq (Conselho Nacional de Desenvolvimento Científico e Tecnológico) e à UNISC (Universidade de Santa Cruz do Sul) pelo auxílio financeiro no desenvolvimento deste trabalho. 